Max-Planck-Institut für demografische Forschung

Max Planck Institute for Demographic Research

Doberaner Strasse $114 \cdot$ D-18057 Rostock · GERMANY

Tel +49 (0) 3812081 - 0; Fax +49 (0) 3812081 - 202;

http://www.demogr.mpg.de

MPIDR WORKING PAPER WP 2002-040

SEPTEMBER 2002

\title{
Patterns of Lowest-Low Fertility in Europe
}

Francesco C. Billari (francesco.billari@uni-bocconi.it) Hans-Peter Kohler (kohler@ demog.berkeley.edu)

(C) Copyright is held by the authors.

Working papers of the Max Planck Institute for Demographic Research receive only limited review. Views or opinions expressed in working papers are attributable to the authors and do not necessarily reflect those of the Institute. 


\title{
Patterns of Lowest-Low Fertility in Europe
}

\author{
Francesco C. Billari Hans-Peter Kohler*
}

September 3, 2002

\begin{abstract}
In this paper we conduct descriptive aggregate analyses to revisit the relation between low and lowest-low period fertility on the one, and cohort fertility and key fertilityrelated behaviors - such as leaving the parental home, marriage and female labor force participation - on the other side. First, we identify a systematic pattern of lowest-low fertility that is characterized by a rapid delay of childbearing, a low progression probability after the first child (but not particularly low levels of first-birth childbearing), and a "falling behind" in cohort fertility at relatively late ages. Second, our analyses show that the cross-country correlations in Europe between the total fertility level on the one side, and the total first marriage rate, the proportion of extramarital births and the female labor force participation rate on the other side have reversed during the period from 1975 to 1999. At the end of the 1990s there is also no longer evidence that divorce levels are negatively associated with fertility levels. Based on these analyses we conclude that the emergence of lowest-low fertility during the 1990s has been accompanied by a disruption or even a reversal of many well-known patterns that have been used to explain cross-country differences in fertility patterns.
\end{abstract}

\section{Introduction}

The majority of the world's population is expected to live in regions with near-replacement or below-replacement fertility in less than 10 years, and the earlier distinct fertility regimes, 'developed' and 'developing', are increasingly disappearing in global comparisons of fertility levels (Bongaarts and Bulatao 2000; Lutz et al. 2001; Wilson 2001). Several aspects of this convergence towards low fertility are particularly striking in this context. First, the spread of below-replacement fertility to formerly high fertility countries has occurred at a remarkably rapid pace and implied a global convergence of fertility indicators that has been quicker than the convergence of many other socioeconomic characteristics. Second, earlier notions that fertility levels may naturally stabilize close to replacement level have

${ }^{*}$ The authors have contributed equally to the paper. Billari is Associate Professor at the Institute of Quantitative Methods, Bocconi University, viale Isonzo 25, I-20135 Milano, Italy, email: francesco.billari@uni-bocconi.it. Kohler is Visiting Professor at the Department of Demography, University of California at Berkeley, 2232 Piedmont Avenue, Berkeley, CA 94720-2120, email: kohler@demog.berkeley.edu, www: http://www.ssc.upenn.edu/ hpkohler. This research was conducted while Billari and Kohler were heads of the research groups on The Demography of Early Adulthood and on Social Dynamics and Fertility at the Max Planck Institute for Demographic Research (MPIDR). Billari and Kohler are most grateful for the support they have received by the MPIDR for this research. The authors also thank Alexia Prskawetz for useful comments and they thank the Observatoire Démographique Européen for providing the cohort fertility data used in our analyses. 
been shattered. In the early 1990s, for instance, Italy and Spain attained lowest-low fertility levels, defined as a TFR below 1.3, and at the end of the 1990s there were 14 lowest-low fertility countries in Southern, Central and Eastern Europe (Kohler et al. 2002). Third, recent fertility trends in developed countries have been accompanied by a remarkable divergence in the fertility levels, ranging in the late 1990s from lowest-low fertility to TFR levels close to 2.1 in the United States.

The new aspect of current low and lowest-low fertility patterns is that the postponement of childbearing - particularly for first births - has emerged as a crucial determinant of differences in fertility levels among developed countries. The reasons for this rapid delay of childbearing in many developed countries seem to be twofold. First, several factors make late childbearing a rational response to socioeconomic changes. These factors include increased incentives to invest in higher education and labor market experience, uncertainty in early adulthood (for instance, due to high youth unemployment of up to 40 percent for women in Southern European countries during the 1990s), general economic uncertainty in Central and Eastern European transition countries, and inefficient housing markets leading to high costs of establishing or expanding independent households. Kohler et al. (2002) argue, however, that these incentives are not sufficient to understand the dynamics of fertility postponement. In addition, social interaction effects are likely to reinforce individual desires to delay childbearing in response to socioeconomic changes in low and lowest-low fertility countries. These interaction effects occur due to social learning and social influence in the decision processes about the timing of fertility (Kohler 2001; Kohler et al. 2001; Montgomery and Casterline 1996), and they can also be caused by feedbacks in the labor and marriage market that make late fertility individually more rational the later the population age-pattern of fertility is. As a consequence of these interaction effects, Kohler et al. (2002) argue that the delay of childbearing follows a postponement transition that shares many characteristics with the fertility transition in Europe or contemporary developing countries. As a consequence of the still ongoing postponement transition, the extent to which specific socioeconomic and institutional contexts accommodate late childbearing has emerged as an essential determinant of cross-country variation in fertility levels in developed countries.

In this paper we therefore conduct a series of descriptive aggregate analyses to revisit the relation between low and lowest-low period fertility on the one, and cohort fertility and key fertility-related behaviors - such as leaving the parental home, marriage and female labor force participation - on the other side. These analyses can improve our understanding of the demographic, socioeconomic and institutional context that is associated with the emergence - or non-emergence - of lowest-low fertility in European countries, and it characterizes the basic demographic and socioeconomic patterns that are associated with low and lowest-low fertility in contemporary Europe.

\section{Period Fertility Trends in Lowest-Low Fertility Countries}

We begin our analyses with an investigation of period and cohort fertility trends in lowestlow fertility countries. For simplicity, we focus these analyses on a subset of countries that 
represent the key lowest-low fertility patterns. In particular, most of our analyses include Italy and Spain, which are the forerunners of lowest-low fertility, the Czech Republic and Hungary, which are Central European countries that exhibit a rapid postponement of fertility during the 1990s, and Bulgaria that represents a transition country with a severe economic crisis in the 1990s and only modest delays of childbearing in the last decade. For comparison, we also include a country that was among the forerunners of the Second Demographic Transition and the initial emergence of below-replacement fertility (Lesthaeghe and van de Kaa 1986; van de Kaa 1987): the Netherlands.

Figure 1 depicts the period total fertility rate and the period mean age at first birth in Bulgaria, the Czech Republic, Hungary, Italy, Spain and the Netherlands. Because small differences in $T F R$ levels become increasingly relevant in low fertility situations, we rescale the $T F R$-axis in this and all subsequent figures so that TFR distances are proportional to differences in stable population growth rates in the stable population. ${ }^{1}$

In 1960, none of these countries in Figure 1a exhibited a total fertility rate of below 2.0, and the three countries with highest TFR levels were the Netherlands, Spain and Italy respectively. The total fertility rate initially declined in the Netherlands, and in the second half of the 1970s the Dutch TFR was the lowest among the countries included in Figure 1. Italy and Spain were the next countries that experienced a rapid and marked fertility decline, and at first this decline seemed to follow the pattern of the Netherlands or other forerunners of the Second Demographic Transition. In the 1980s, however, an important divergence occurs between the Netherlands on the one hand and Italy and Spain on the other: the Dutch total fertility rate stabilized and reversed after reaching a trough of 1.47 in 1983, in the late 1990s the total fertility increased again to 1.65. In contrast, the Italian and Spanish TFRs continued to decline without such a stabilization at moderate below-replacement levels. In the late 1980s, the Italian and Spanish total fertility rates dropped below the Dutch TFR, and in 1990 Italy and Spain exhibit the lowest fertility rate in Figure 1 by a substantial margin.

After Italy and Spain, lowest-low fertility spread to Central and Eastern Europe (CEE) where the political and economic transition after 1990 has been associated with substantial economic hardship and uncertainty (e.g., Kohler and Kohler 2002; Kohlmann and Zuev 2001; Philipov 2001) and marked demographic changes (e.g., Cornia and Paniccià 2000; Kučera et al. 2000). Representative for this experience of Central and Eastern European countries, we depict in Figure 1 the total fertility of Bulgaria, the Czech Republic and Hungary. The figure shows that after some turbulences and marked changes prior to 1980s, frequently related to adjustments of family policies (e.g., Frejka 1980), the total fertility rate in these countries has been relatively stable. In the early 1990s, however, a major break occurs, and TFR levels rapidly decline to unprecedented low levels. This drop in fertility rates has been very pronounced and swift, and many Central and Eastern European countries - including Hungary, the Czech Republic and Bulgaria in Figure 1attained lowest-low fertility during the mid to late 1990s.

\footnotetext{
${ }^{1}$ These calculations are based on a mean age at birth of 30 years, which is a roughly representative mean age for contemporary Western European countries, and a proportion of girls among all births of 4886 .
} 
Figure 1: Period total fertility rate and period mean age at first birth in Bulgaria, the Czech Republic, Hungary, Italy, Spain and the Netherlands (Source: Council of Europe (2001))

\section{(a) Total fertility rate}

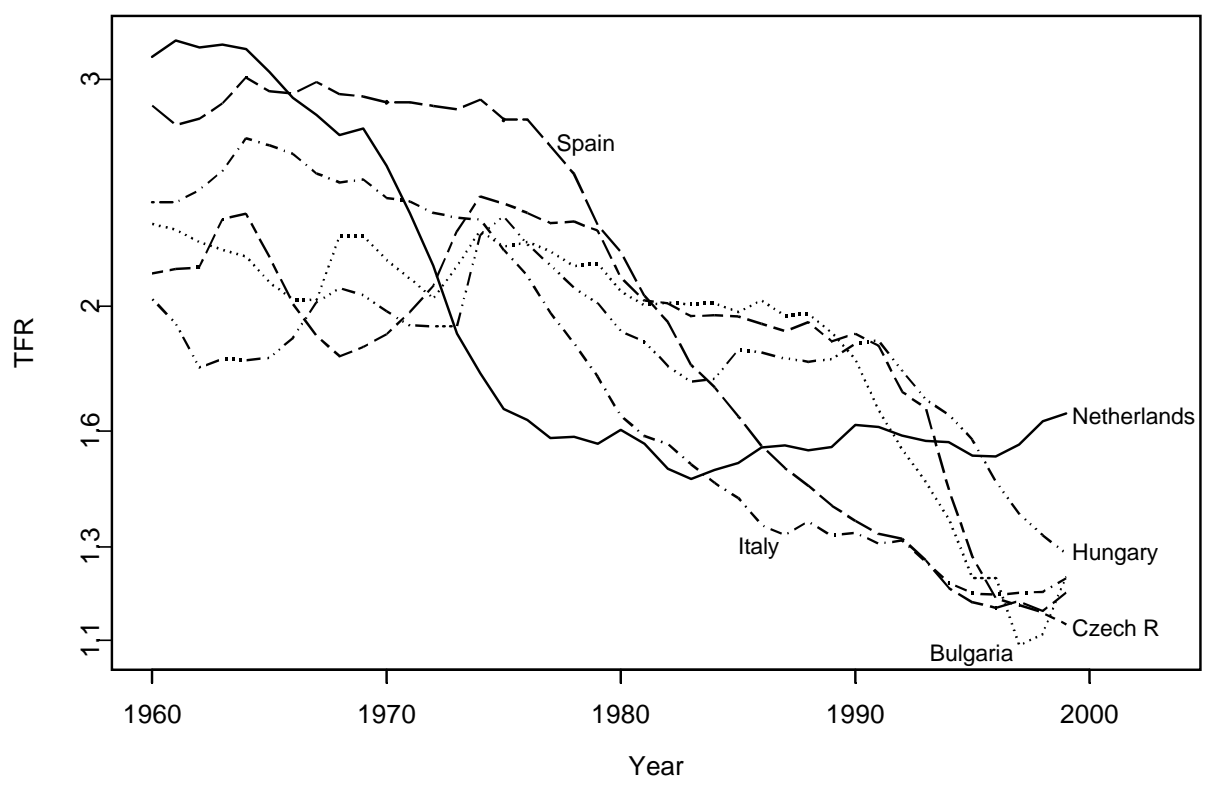

(b) Mean age at first birth

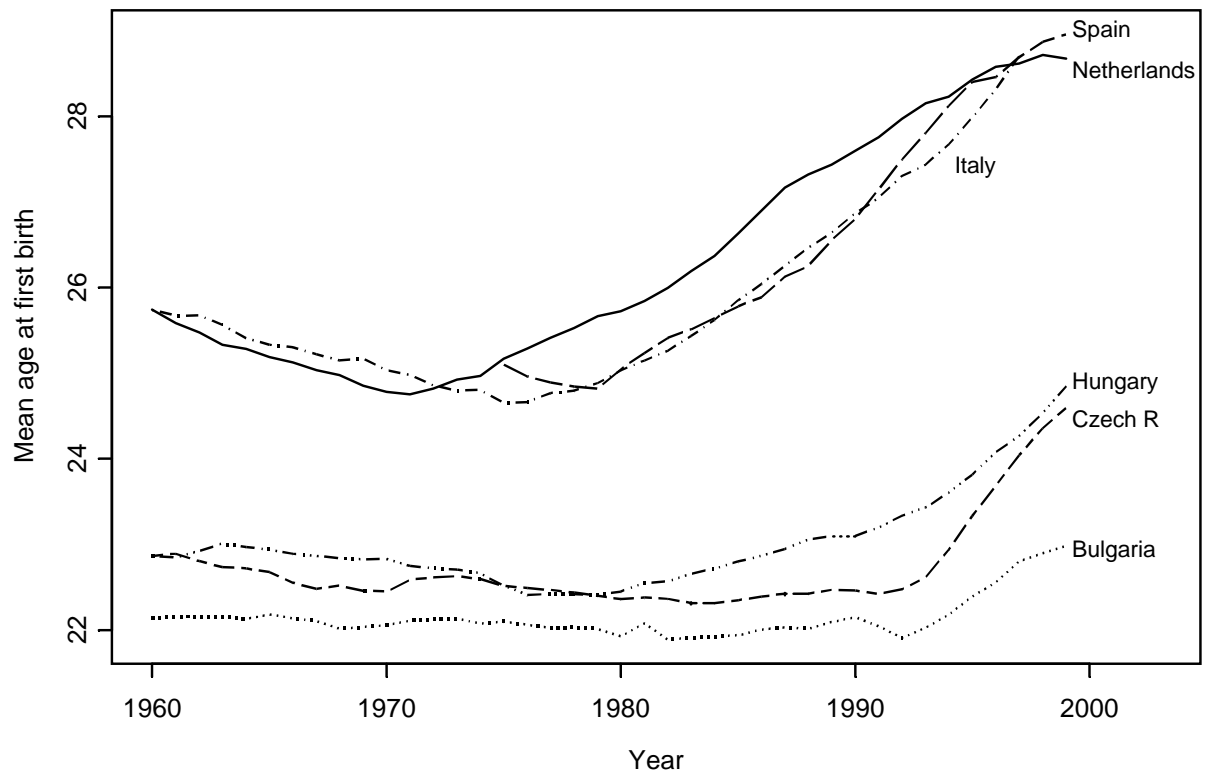

Note: In this and all subsequent figures, the $T F R$ axis has been rescaled so that $T F R$ distances are proportional to differences in stable population growth rates in the stable population. These calculations are based on a mean age at birth of 30 years, which is a roughly representative mean age for contemporary Western European countries, and a proportion of girls among all births of .4886. 
The emergence of lowest-low fertility in Europe during the 1990s has been associated with a substantial delay of childbearing in most countries, and the countries in Figure 1 are no exception. During the 1990s, for instance, the mean age at first birth increased by more than 1.5 years in Italy, Spain, Hungary and the Czech Republic. The change is even more pronounced since the early 1980s: the increase in the mean age at first birth exceeds 3.5 years in Italy and Spain and 2.2 years in Hungary and the Czech Republic (Council of Europe 2001). At the same time, it is important to note two deviations from this nexus between lowest-low fertility and substantial delays in childbearing. On the one hand, a rapid and marked postponement does not necessarily imply lowest-low fertility: the Netherlands - along with other Nordic countries not analyzed here- have experienced a comparable increase in the period mean age at first birth during the 1980s and 1990s, but this postponement has not been associated with substantial declines in period fertility levels (Figure 1b). On the other hand, lowest-low fertility is also not inevitably associated with a rapid delay of childbearing. For instance, the postponement in Bulgaria during the 1990s lags behind that of the remaining countries in Figure 1(b), and the mean age at first birth increased by only .8 years during the transition period in the 1990s. Bulgaria therefore attained lowest-low fertility levels without substantial delays in the timing of first births, and this pattern is shared by Russia and other several formerly Soviet Republics (see Kohler and Kohler 2002).

A further divergence between the lowest-low fertility countries in Figure 1 occurs with respect to the onset of fertility postponement and the total delay of childbearing that has already occurred. In particular, Italy and Spain have experienced an increasing mean age at first birth since the mid- to late 1970s, and in combination with a relatively high mean age at first birth at the onset, these countries have attained among the latest patterns of childbearing in Europe. In contrast to these Southern European countries, the postponement of childbearing in the Central and Eastern European countries is still a relatively recent phenomenon that represents a break with a prolonged period of early fertility and marriage (see Hajnal 1965 for an early, and Coleman 1996 for a more recent discussion). This Eastern European pattern can be further distinguished with respect to the onset of fertility postponement. On the one hand, Hungary started its delay of first births in the 1980s and the 1990s are merely associated with a faster pace of an already ongoing postponement process. The delay of parenthood in the Czech Republic and Bulgaria, on the other hand, is only initiated with the transition process in the early 1990s. It then occurs at a very rapid pace in the Czech Republic, leading to a convergence in the mean age at first birth with Hungary, and it proceeds at a much more modest speed in Bulgaria, which continues to exhibit the lowest mean age at first birth in Figure 1(b) also at the end of the 1990s.

\section{Cohort Fertility Trends in Lowest-Low Fertility Countries}

An essential issue in the context of lowest-low fertility is the question of how periods with TFR levels below 1.3 affect cohort fertility. On the one hand, the effect is modest if lowest-low fertility is only temporary and births are merely postponed but not foregone. 
Figure 2: Completed cohort fertility in Bulgaria, the Czech Republic, Hungary, Italy, Spain and the Netherlands

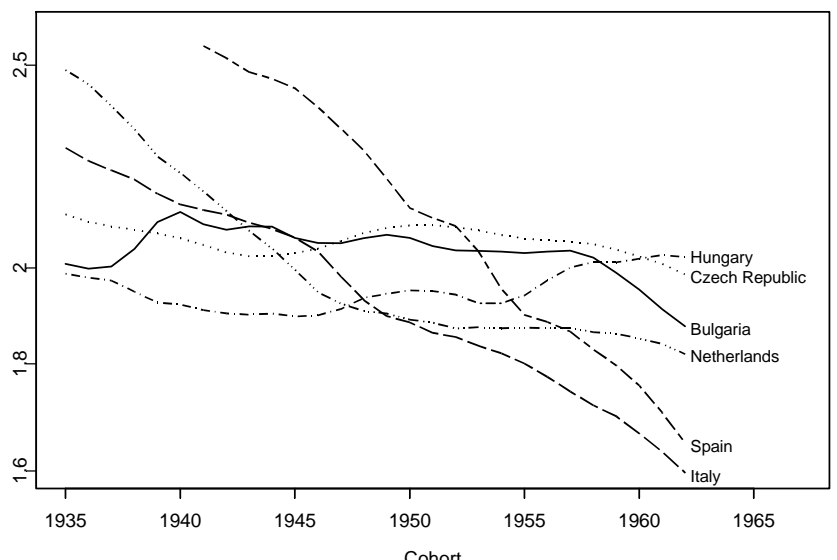

Note: Cohort fertility has been rescaled so that distances are proportional to differences in stable population growth rates in the stable population; see notes to Figure 1 for discussion. Source for data: (Council of Europe 2001).

On the other hand, the implications of lowest-low TFR levels on cohort fertility are severe if lowest-low fertility persists and if it is caused by reductions in completed fertility levels instead of changes in the timing of fertility.

In this section, we study patterns of cohort fertility as far as they have been revealed until the 1990s. ${ }^{2}$ We begin our investigations with the trends in completed cohort fertility, and Figure 2 shows that the differences and divergences in period TFR trends, on which we focused in the previous section, have their counterparts in cohort fertility patterns. First, cohort fertility in Hungary, the Czech Republic and Bulgaria have been relatively stable: across all cohorts born between 1935 and 1962, completed cohort fertility in these three countries remained within the interval ranging from 1.87 and 2.13 children, and there have been no marked downward or upwards trends - with the potential exception of Hungary, where cohort fertility increased starting for women born after 1955 due to pronatalistic family policies. The interpretation of these stable cohort fertility levels, however, evolves over time due to the shift in the relative position of these countries within Figure 2 (and also within European countries more generally). While fertility levels in Hungary, the Czech Republic and Bulgaria were the lowest for cohorts born prior to the end of WWII, these Central European countries exhibit the highest level of fertility for cohorts born in the late 1950s and early 1960s. This reversal is due to the substantial declines of cohort fertility in the other countries. For instance, Dutch fertility declined markedly in all cohorts born after 1935 from a level of almost 2.5, and then stabilized at a level around 1.9 for cohorts born after 1950. Substantial declines in cohort fertility have also occurred in Italy and especially Spain, but there has been no stabilization until the early 1960s.

\footnotetext{
${ }^{2}$ The data on completed cohort fertility is taken from Council of Europe (2001). The age-pattern of cohort fertility for the more detailed analyses have been obtained from the Observatoire Démographique Européen for Italy, Hungary, the Czech Republic and Bulgaria, and comparable data for the Netherlands has been provided by Evert van Imhoff at the Netherlands Interdisciplinary Demographic Institute (NIDI). The data include age- and parity specific childbearing intensities (rates of the first kind) and fertility rates (rates of the second kind) for cohorts born from approximately the 1930s onward.
} 
As a consequence, for women born after 1949, Italian cohort fertility represents the lowest level among all countries in Figure 2; it is only followed by Spain, where cohort fertility has been declining more recently, but at a faster pace and to a larger extent than in Italy.

The above analyses of completed cohort fertility are no longer feasible for women born from the early 1960 onwards because these women have not yet completed childbearing as of 1999. An alternative in this situation is to study cumulated fertility, that is, the number of children that have been born to women at various ages up to the most recent calendar year. In order to provide a context and reference for these analyses, this study of cumulated fertility is often conducted relative to a reference cohort (e.g., Frejka and Calot 2001a,b,c). In this case, instead of being based on the absolute level of fertility, the analyses focus on the differences between the cumulated fertility of women born in a calendar year and the number of children that have been born to women in the reference cohort. Figure 3, for instance, depicts the difference in the cumulated cohort fertility, separately for first births and all birth orders combined, between women born 1955-1975 and women in the reference cohort born in 1950. For Italy, these analyses reveal the following cohort fertility pattern: At age 30, for example, women in the Italian cohort born in 1965 had on average .22 fewer first children and .54 fewer children in total as the cohort born in 1950. This difference in fertility level to the reference cohort increases for younger women. At age 25, for instance, Italian women born in 1970 had .33 fewer first and .54 fewer total children than the 1950 cohort, and it is likely that this difference further widens as the cohort reaches its late twenties.

The graphs in Figure 3 also reveal the extent to which differences in fertility levels across cohorts are due to a postponement of fertility. The Italian cohort born in 1960, for example, 'lagged' behind the 1950 reference cohort and had on average about .15 fewer first births at age 26. When the age of this cohort reached the late twenties and early thirties, however, this gap was reduced and fertility for first births was partially recuperated. At age 35 it had only .067 fewer first children than the reference cohort, while the difference in overall fertility declined only slightly from .32 at age 29 to .26 at age 35. Recuperation of postponed births, therefore, reveals itself in Figure 3 by a Ushaped pattern: the line representing the cumulated fertility of a cohort initially declines as the difference to the reference cohort grows, then reaches a trough, and reverses and moves towards zero as the difference to the reference cohort diminishes. If there is 'perfect' recuperation, the difference will diminish completely, and partial recuperation implies a persistent difference also at the end of childbearing ages. The Italian cohort born in 1955 reflects such partial recuperation as compared to the 1950 reference cohort, and a similar pattern is likely to prevail in the 1960 and younger cohorts (for further discussions, see Frejka and Calot 2001a).

The pattern for the Czech Republic in Figure 3 differs from the Italian one due to the relatively stable cohort fertility prior to the early 1960s. For instance, the cohorts born 1955-70 exhibit slightly higher fertility than the 1950 reference cohort at relatively young ages, and they 'fall behind' the reference cohort only at ages from the mid to late twenties onwards. For the 1955-60 cohorts the ultimate fertility difference at age 40 is very small, while it is likely to remain somewhat larger for the 1965 cohort. This pattern alters once 


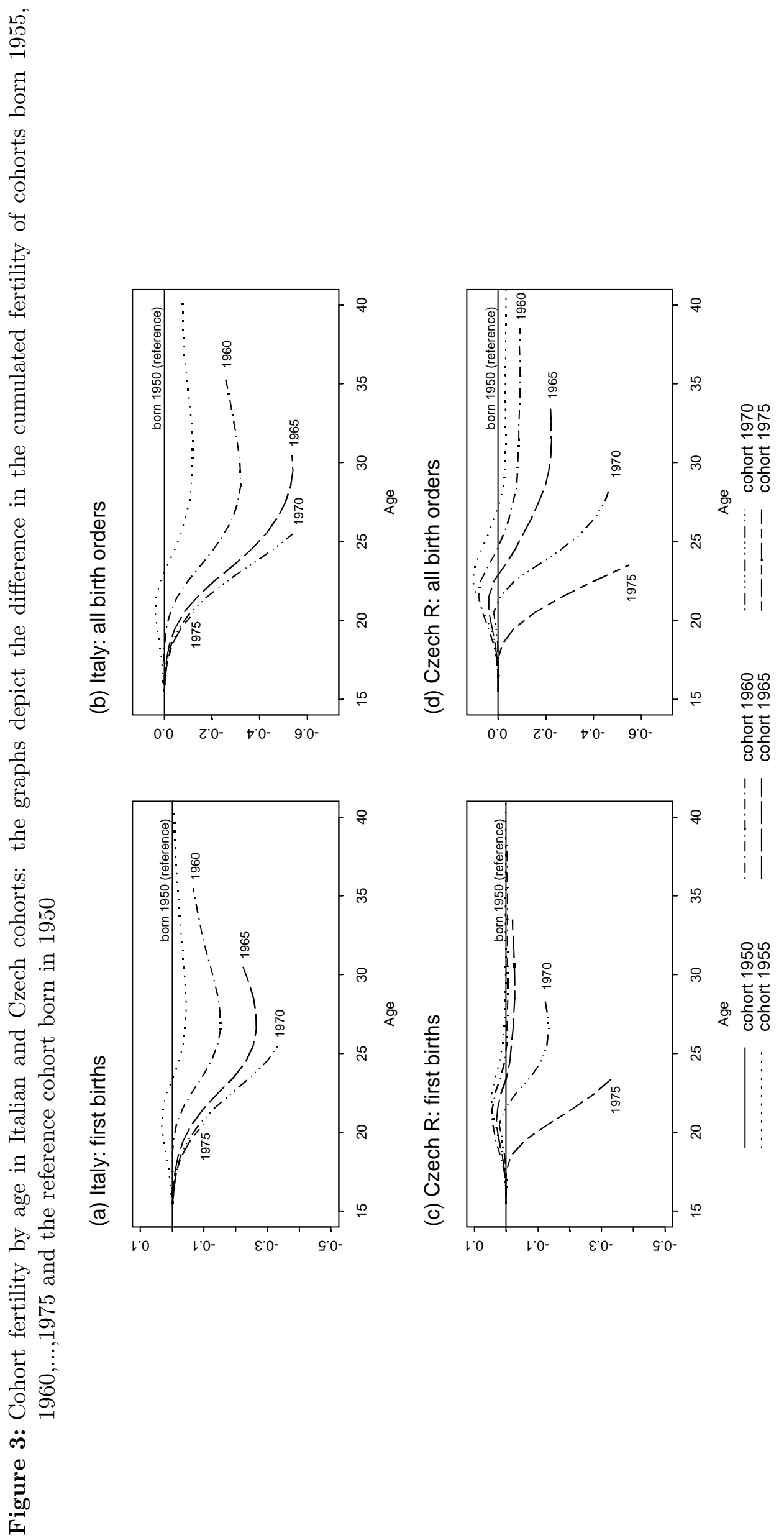


Figure 4: Cohort fertility by age in Dutch cohorts: the graphs depict the difference in the cumulated fertility of cohorts born 1955, 1960,..,1975 and the reference cohort born in 1950

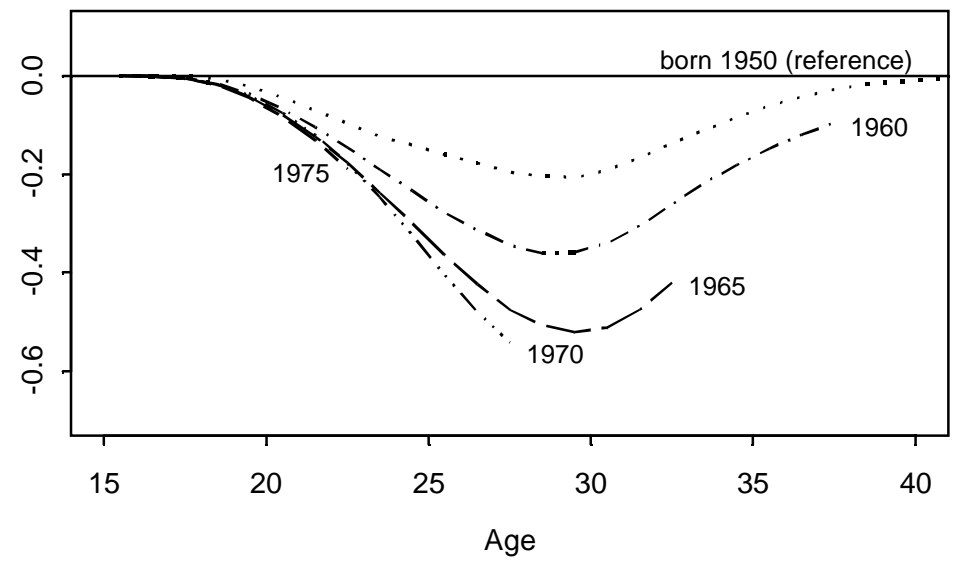

we consider cohorts that have experienced a substantial part of their reproductive ages during the transition period in the 1990s. For instance, women in the 1970 cohort have on average .47 fewer than the 1950 cohort at age 28 , and the level of first birth fertility in the 1975 cohort at age 23 is by more than .33 below that of the 1950 cohort. This gap is even more pronounced for completed fertility, where the 1970 cohort exhibits a fertility level at age 23 that is .55 children below that of the reference cohort.

A common pattern for Italy and the Czech Republic in Figure 3 is the gradually increasing difference in cumulated fertility to the reference cohort in early adulthood, where union formation and first-birth childbearing has traditionally been concentrated. The same situation also prevails in Hungary and Bulgaria (see Appendix Figure A 1, and in several other European countries (Frejka and Calot 2001a,b,c). Frejka and Calot (2001a) have denoted this difference in cumulated fertility to the reference cohort as a fertility deficit, and they have taken the increasing deficit during early adulthood in younger cohorts as an indication that cohort fertility in Italy and several other countries is likely to remain substantially below that of the 1950 cohorts. $^{3}$

While we do not necessarily disagree with this conclusion about further declines in completed cohort fertility, the usefulness of this finding for assessing lowest-low fertility is limited. In particular, as with many comparisons, the conclusion hinges critically on the choice of the reference cohort. In addition, the above comparisons do not reveal the fact that there are substantial differences in the timing of fertility and its recuperation across different countries, and the analyses do also not reveal the extent to which delays in childbearing have been associated with trends towards low and lowest-low fertility.

As a counter-example to the Italian and Czech patterns, we therefore present in Figure 4 the cohort fertility trends in the Netherlands, which have been characterized by substantial delays in childbearing without marked declines in cohort fertility levels. Thus,

\footnotetext{
${ }^{3}$ The notion of fertility deficit, and its counterpart, fertility surplus is also somewhat unfortunate since it tends to imply that the reference cohort reflects a "correct" or "desirable" fertility pattern, and deviations from this pattern in younger cohorts constitute either surpluses or deficits that are positively or negatively evaluated by demographers.
} 
while younger cohorts in Figure 4 exhibit a growing 'fertility deficit' during early adulthood, there is a successful recuperation of delayed births. In particular, the difference in cumulated fertility to the 1950 reference cohort attains a maximum at ages in the late twenties for cohorts born during 1955-70, and it then declines as these cohorts age and enter their thirties. Moreover, the difference almost diminishes for women born in 1955 and 1960. Whether the same holds for the 1965 cohorts is difficult to assess on the basis of our present analyses, but Figure 4 clearly indicates that the difference is going to lessen also for the 1965 cohort before it ends its childbearing years.

In order to understand the implications of delayed childbearing on cohort fertility, the Netherlands may therefore serve as a 'role model' for lowest-low fertility countries: women in the Netherlands delayed the onset of childbearing to very late ages in comparison with other European countries, but this postponement occurred without substantially reducing the quantum of fertility, or equivalently, the number of children born during the life-course. A comparison of cohort fertility patterns in lowest-low fertility countries with the Dutch cohort patterns may therefore be very illuminating, and we replicate our earlier analyses using the Dutch cohort fertility pattern as reference (Figure 5). In particular, instead of measuring the difference in cumulated fertility to the 1950 cohort, we present in Figure 5 the difference in the cumulated cohort fertility between Italian or Czech cohorts and Dutch cohorts born in the same year. That is, the fertility pattern of the 1960 cohort in Italy is compared to the 1960 cohort in the Netherlands, the 1965 Italian cohort is compared to the 1965 Dutch cohort, and so forth.

While our earlier analyses indicated growing fertility deficits in younger cohorts in Italy and the Czech Republic, our investigations in Figure 5 provide a striking contrast: all cohorts born during 1950-75 in Italy and the Czech Republic exhibit a higher cumulated fertility in early adulthood than the corresponding Dutch cohorts born in the same year (the same pattern also holds for Hungary and Bulgaria; see Appendix Figure A 2). ${ }^{4}$ The analyses in Figure 5 therefore suggest that lowest-low fertility is not necessarily related to the fact that fertility rates in early adulthood, or until the mid twenties, are particularly low - quite on the contrary: some key lowest-low fertility countries such as Italy, the Czech Republic, Hungary and Bulgaria exhibit a higher cohort fertility during the early adulthood than cohorts in the Netherlands born in the same year. This is particularly important since the Netherlands are characterized by relatively high period and cohort fertility rates in a European comparison in the late 1990s, and the Netherlands are sometimes portrayed as a 'success story' with respect to adjusting to demographic challenges provided by the fertility patterns of the 1990s (e.g., Lesthaeghe 2001; van Imhoff 2001).

The 'fertility surplus' of lowest-low fertility countries during early adulthood is particularly large in the Czech Republic and other CEE countries that are still characterized by a relatively young pattern of childbearing. For instance, the surplus exceeds .4 first children and .6 total children at age 25 for cohorts born prior to 1975 , and it has markedly declined only in the most recent cohort born in 1970. Despite this recent decline, the

\footnotetext{
${ }^{4}$ Kreyenfeld (2002) has also found a similar pattern in companions of East and West German cohort fertility patterns, where young East German cohort tend to have more children as their West German counterparts, despite the fact that the East German total fertility rate has been substantially lower than the West German TFR during the 1990s.
} 


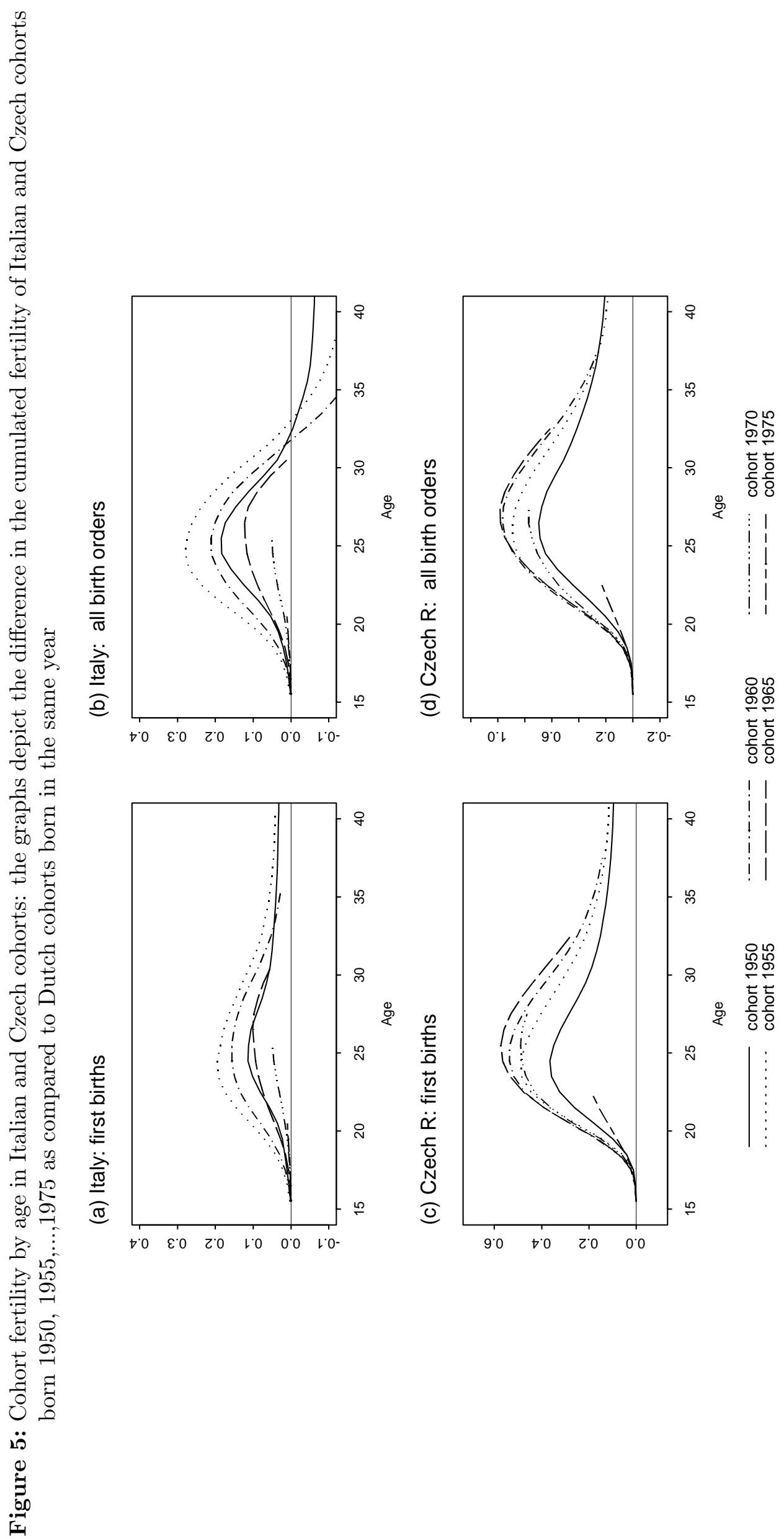


comparison between the Czech and Dutch cohort patterns suggests that fertility even in young Czech cohorts may not decline below the levels observed in the Netherlands. Moreover, the 'surplus' in early adulthood even opens the possibility that cohort fertility in the Czech Republic - and other CEE countries - remains above that of many Western European countries for the foreseeable future if period fertility trends stabilize or reverse. Whether lowest-low fertility in CEE countries therefore implies lowest-low cohort fertility is very questionable, and it depends to a substantial extent on the future trends in period fertility.

In comparison to this Czech pattern, the Italian 'fertility surplus' in Figure 5 is more modest and reaches a maximum of only .19 for first births and .28 for all birth orders combined around age 25. Despite the less remarkable fertility difference in comparison to the Netherlands, a more detailed look at the Italian pattern is revealing with respect to the determinants of lowest-low fertility. In particular, the difference in Figure 5(a) is positive for all cohorts across all ages at which cohorts are observed, suggesting that all Italian cohorts born during 1950-75 seem to be ahead of the corresponding Dutch cohorts in terms of first birth childbearing. The emergence of lowest-low fertility in Italy, therefore, does not seem to be due to the fact that Italian cohorts have their first children at a particularly slow rate - on the contrary, Italian women in young cohorts born up to 1975 have more first children than Dutch women in the same cohorts, despite the fact that the total fertility rate in the Netherlands exceeds that of Italy by $35-40 \%$ in the late $1990 \mathrm{~s}$.

This fertility surplus also prevails at young ages when all birth orders are combined. Italian cohorts have more children than their Dutch counterparts in their early twenties, Italian cohorts born up to 1965 even had more children than the respective Dutch women until they reached age 30. An important reversal, however, occurs around age 30, and Italian cohorts fall behind the corresponding cohorts in the Netherlands in terms of cumulated fertility. For the cohort born in 1950 this reversal is very modest, and Italian women have only about .06 children less than their Dutch cohort-mates. The difference, however, increases in younger cohorts. For instance, the Italian cohort born in 1960 has .15 fewer children at age 35 than the respective Dutch cohort, and it seems likely that the gap increases further for women born in 1965.

On a cohort level, therefore, the Italian lowest-low fertility pattern is not characterized by few first births or a particularly low fertility in early adulthood. Quite on the contrary, Italian cohorts tend to be ahead of their Dutch cohort mates in terms of first births and overall fertility level until they reach their mid 20s (cohort 1970) or even late twenties and early thirties (cohorts born up to 1965). The Italian lowest-low fertility pattern, however, is characterized by a 'falling behind' later in the life-course when the progression to births of higher parities becomes increasingly relevant.

\section{Fertility-Related Patterns of Household and Union Dy- namics}

The patterns of lowest-low fertility described in the previous section are closely related to cross-country differences in the processes of union formation and dissolution to which 
we turn our attention in the present section. This investigation of union formation and dissolution is motivated by the fact that earlier analyses of the transition from high to low fertility focused to a large extent on the decline of marital fertility. In particular, since fertility before and during the first demographic transition was almost totally realized within marital unions, the timing and prevalence of marriage was seen as one of the key mediating factors, or proximate determinants, that affected fertility levels (Bongaarts 1978). After the emergence of low fertility, and especially in forerunners of the Second Demographic Transition like Sweden and partially also the Netherlands, marriage has lost its central role in being a precondition to childbearing. Nevertheless, in most European countries besides the United Kingdom, almost the totality of births take place within a co-resident partnership (either cohabiting or married), and the rise of extra-marital childbearing is mostly due to the diffusion of cohabitation (Kiernan 1999).

In order to provide a conceptual framework for these changes in union formation and dissolution, we adopt in our analyses the perspective of life-course transitions and lifecourse decision-making. In this framework the decision to become a parent is embedded in a process that involves several transitions in early adulthood that ultimately lead to the separation from the parental home to entry into a union and entry into parenthood (Modell et al. 1976). The central transitions in early adulthood, which also receive the largest attention in life-course studies, are therefore the formation of a separate household from one's parents (leaving the parental home), the formation of an union with a partner (union formation), and the transition to the first child. We consider these two transitions in turn.

\subsection{Leaving the Parental Home: Latest-Late and Lowest-Low?}

Leaving home is one of the crucial nodes of the life-course and a central event in early adulthood. First, it generally implies the formation of a new household and greater autonomy for young people in all aspects of social life and personal decision-making, including also many fertility-related decisions. Second, and most important for our context, childbearing in developed countries almost invariably takes place after young adults have left their parental home, and home-leaving constitutes a central correlate of fertility and union formation in Europe and other industrialized countries.

Patterns of home-leaving are therefore an important aspect of understanding contemporary fertility differences and trends, including also the emergence of lowest-low fertility during the 1990s. In a pioneering study, Kiernan (1986) investigates home-leaving in six Western European countries in 1982. The study identifies Denmark as the country with the earliest home-leaving, followed by West Germany, France, the Netherlands, Ireland and the UK. In a follow-up investigation, Fernández Cordón (1997) examined the living arrangements of young adults over time in Spain, Greece, Italy, France, Germany and the UK between 1986 and 1994. These longitudinal analyses revealed that Italy had the highest share of young people co-residing with their parents during early adulthood, while the UK had the smallest share. Moreover, the cohort trend towards delayed childbearing has its counterpart in the timing of home-leaving, and Corijn (1999) found that cohorts in most European countries born around 1950 and 1960 were postponing the transition out of 
Figure 6: Relationship between median age at leaving home and TFR (women)

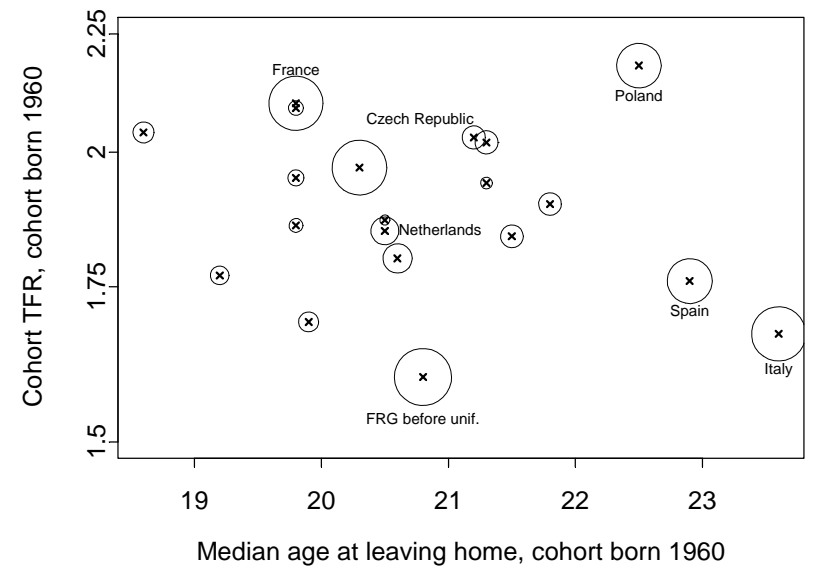

Note: The ' $X$ ' mark gives the exact position of a country, while the area of circle is proportional to the country's population size in 1990. Sources for data: Billari et al. (2001); Council of Europe (2001)

the parental home. This common trend towards delayed home-leaving, however, co-exists with substantial variation in the timing of this event across countries. In particular, Corijn (1999) finds that Italy and Spain are among the countries with a late separation from the parental home, while Austria, the Netherlands and Sweden were among the countries with an early pattern.

Despite this overall heterogeneity in patterns of homeleaving, however, there is an important regularity with respect to the relation of homeleaving and lowest-low fertility. In particular, the timing of home-leaving is quite homogeneously concentrated at relatively late ages among lowest-low fertility countries. On the one hand, Italy, which is the first country experiencing lowest-low fertility in the early nineties, has the highest age both for men and for women with 26.7 years and 23.6 years respectively. Some Central and Eastern European countries, including those with lowest-low fertility, are not distant from the latest-late pattern of Southern European countries. On the other hand, Sweden represents the opposite side of the ranking with 20.2 years for men and 18.6 for women, resulting in a difference of more than 6.5 years (males) and 5 years (females) in the timing of homeleaving across European countries (for further analyses, see Billari et al. 2001). ${ }^{5}$ This association between late homeleaving and low fertility persists in a cohort perspective. Figure 6, for instance, compares the median age at home-leaving for the cohort born in 1960 with the completed fertility levels $(C T F R)$, and the figure reveals a clear negative association between median age at home-leaving and total fertility. On the one hand, all countries with very late - or latest-late - homeleaving in Figure 6 are also exhibit lowestlow fertility; on the other hand, not all lowest-low fertility countries are characterized by late home-leaving, and there is considerable heterogeneity in completed fertility among countries with earlier separation from the parental home. (In order to indicate the relevance of data points in Figure 6 and subsequent figures, the data points are surrounded by circles

\footnotetext{
${ }^{5}$ The analyses are based on family and fertility surveys (FFS) that were conducted in many European countries during the early 1990s; see (Billari et al. 2001) for details. For Bulgaria, the data unfortunately are not available.
} 
that have an area proportional to a country's population size in 1990).

\subsection{Fertility and Marriage: A Shifting Relationship?}

While home-leaving of young adults leads to the formation of a separate household, this event is event is no longer closely tied in all societies to marriage and childbearing. Quite on the contrary, we present in this section evidence that the relation between marriage and fertility has been fundamentally transformed in recent decades.

In a well-known study, Hajnal (1965) traces an East-West divide in historical family systems in Europe, and the so-called Hajnal line connects the cities of Trieste in NorthEastern Italy and St. Petersburg in Western Russia. To the West of this line, the family formation pattern is dominated by a neo-local nuclear family with relatively late marriage and a significant proportion of individuals who never marry. To the east of Hajnal's line, marriage has been early and universal, and the family is often extended. This divergence of marriage pattern along Hajnal's like also prevails after WWII and persists until the present time. It is particularly pronounced between Central and Eastern Europe on the one and Southern Europe on the other side Monnier and Rychtarikova (1992), while countries to the west of Hajnal's line reveal greater heterogeneity and diversity in contemporary marriage behaviors that do not easily cluster into a single pattern (Reher 1998).

Even if historical patterns are an important aspect shaping present marriage behaviors and family organizations, the emergence of lowest-low fertility is associated with an important shift of the relationship between marriage and fertility between the mid 1970s and the end of the 1990s. In particular, it has traditionally been argued that cumulated fertility is inversely related to age at marriage, and variations in the age at marriage have often been an important explanatory factor of aggregate fertility differences across countries. For instance, a linear relationship between TFR and age at first marriage has shown surprisingly good approximation (Henry 1976; Inaba 1996), and Billari et al. (2000) estimate that a one-year increase in the age at marriage would bring down the number of female children ever born by about 0.08 in Italian cohorts born around 1950 .

In contrast to this positive association between marriage and fertility, the recent emergence of lowest-low fertility, especially in Southern Europe, is associated with a situation in which long-term partnership commitments - symbolized by a legal marriage and low divorce rates - apparently represent an obstacle for the progression to (relatively) high fertility levels. To illustrate this association, we compare on the left-hand side of Figure 7 the period total fertility rate $(T F R)$ with the the period total first marriage rate $(T F M R) .{ }^{6}$ In 1975, Figure 7a shows that marriage and fertility were still closely intertwined and there has been a positive correlation between the TFR and the total first marriage rate. This picture radically changes at the end of the 1990s. In particularly, after lowest-low fertility has emerged, the positive correlation between TFR and TFMR is much weaker, and countries with high fertility levels also exhibit low marriage propensity (Figure 7c). A similarly shifting relation occurs also with respect to fertility and divorce (Figure $7 \mathrm{~b}, \mathrm{~d}$ ). In 1975, a higher level of divorce in European countries was associated with lower levels of

\footnotetext{
${ }^{6} \mathrm{~A}$ caveat of the total first marriage rate $(T F M R)$ is that it is subject to the same limitations and distortions as the total fertility rate as a measure of "marriage quantum".
} 

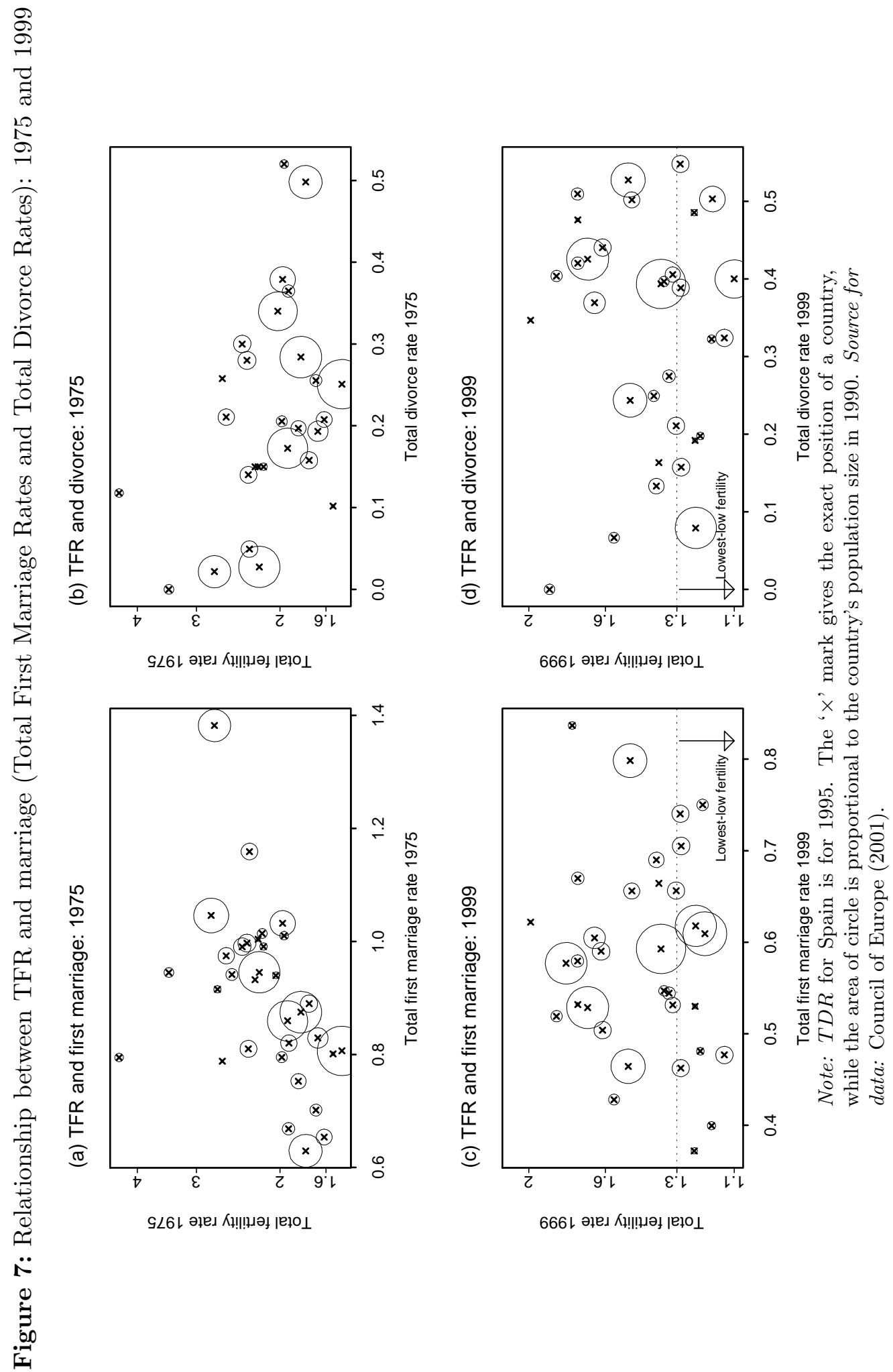
Figure 8: Proportion of extra-marital births and TFR, 1975 and 1999

(a) TFR and extra-marital fertility: 1975

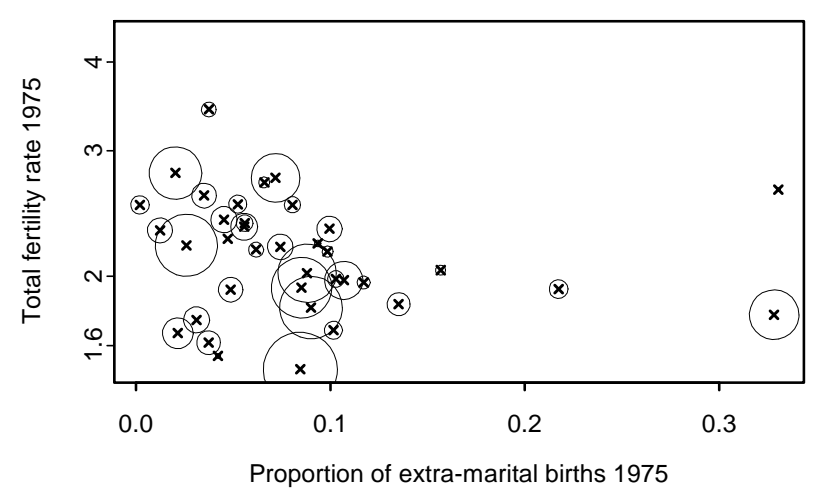

(b) TFR and extra-marital fertility: 1999

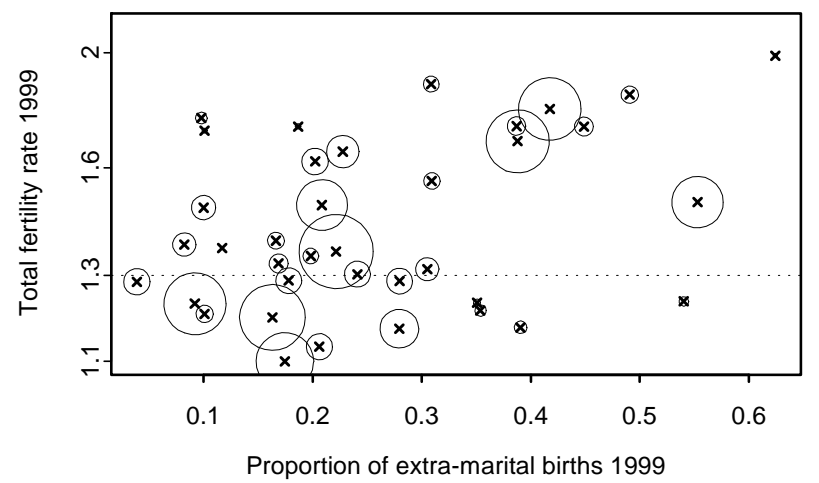

Note: $T D R$ for Spain is for 1995 . The ' $\times$ ' mark gives the exact position of a country, while the area of circle is proportional to the country's population size in 1990. Source for data: Council of Europe (2001)

fertility in cross-sectional comparisons, and the period total divorce rate $(T D R)$, and the $T D R$ exhibits a negative correlation with the $T F R$ (Figure $7 \mathrm{~b}$ ). This correlation becomes weak in 1999, and if a systematic relationship exists at all between the TDR and the $T F R$ in 1999, the sign of the correlation has reversed: countries with higher TDR do also have higher fertility levels (Figure $7 \mathrm{~d}$ ). In Figure 8 we additionally illustrate that the relationship between the extent of out-of-wedlock childbearing and the level of fertility has reversed along with the shifting centrality of marriage. In particular, a cross-sectional comparison on European countries in 1975 reveals a positive correlation between the level of extra-marital fertility and the total fertility rate. In 1999, this correlation has become negative, and along with this reversal, the Southern European countries, Italy and Spain, stand out as combining both lowest-low fertility and the lowest prevalence of non-marital fertility.

In summary, the above analyses reinforce our argument that the emergence of lowestlow fertility during the 1990s has been associated with fundamental shifts in the relationships between fertility and marriage. In particular, there has been an increasing disconnection between marriage patterns and fertility levels after the emergence of lowest-low fertility in the 1990s in cross-sectional analyses of European countries, and marriage formation and dissolution are no longer important predictors of national fertility levels in 
Table 1: The timing of life-course transitions in early adulthood and completed fertility for cohorts centered on 1960 in Bulgaria, Czech Republic, Hungary, Italy, Spain, and The Netherlands.

\begin{tabular}{lcccc}
\hline \multicolumn{4}{c}{ Median age at } \\
\cline { 2 - 4 } & $\begin{array}{c}\text { leaving } \\
\text { home }\end{array}$ & $\begin{array}{c}\text { first } \\
\text { union }\end{array}$ & $\begin{array}{c}\text { first } \\
\text { marriage }\end{array}$ & $\begin{array}{c}1960 \\
\text { CTFR }\end{array}$ \\
\hline Bulgaria & n.a. & 21.1 & 21.1 & 1.95 \\
Czech Republic & 21.2 & 20.4 & 20.7 & 2.03 \\
Hungary & 21.3 & 20.3 & 20.6 & 2.02 \\
Italy & 23.6 & 23.8 & 24.0 & 1.67 \\
Spain & 22.9 & 23.3 & 23.6 & 1.76 \\
Netherlands & 20.5 & 21.1 & n.a. & 1.85 \\
\hline
\end{tabular}

Notes: n.a.=data not available. Source: Billari et al.

(2001); Council of Europe (2001)

cross-sectional analyses of European countries during the late 1990s.

\subsection{Two Household and Union Formation Patterns among Lowest-Low Fertility Countries?}

In this section we extend our previous analyses and argue that lowest-low fertility countries in the late 1990s are characterized by two distinct patterns of union formation that are closely related to their historical precursors and historical patterns of family organization.

In Table 1 we begin with the cohort perspective and report the median age at leaving home, the median age at first union, the median age at first marriage, and the completed fertility (CTFR) of the 1960 cohort (or of 5 year cohorts centered on 1960) for selected lowest-low fertility countries and the Netherlands. On the one hand, the table reveals that Bulgaria, the Czech Republic and Hungary share a relatively early age at leaving home, a relatively early age at union formation, and a relatively high completed fertility level $(C T F R)$ with the Netherlands, which is a forerunner of the Second Demographic Transition. On the other hand, Italy and Spain are characterized by a late age at leaving home, a late age at first union and a low level of completed cohort fertility. Among lowestlow fertility countries in Table 1, there is hence a clear negative relationship between the timing of household and union formation and the quantum of fertility on the cohort level. ${ }^{7}$

In Table 2 we shift from a cohort to period perspective and investigate the patterns of the marriage, divorce and fertility in 1999. Once a period pattern is adopted, the picture becomes slightly more heterogeneous as compared to the above cohort analyses. Bulgaria, Czech Republic, and Hungary exhibit a total first marriage rate (TFMR) around 0.5 (with the lowest level of 0.46 in Hungary), while Italy and Spain have somewhat higher TFMR close to 0.6. In the Netherlands, marriage still has an important role with a

\footnotetext{
${ }^{7}$ One needs to keep in mind, however, that the 1960 cohort in Bulgaria, the Czech Republic and Hungary basically completed union formation, first-birth childbearing and in part also fertility at higher parities during the socialist periods in prior to the transition beginning in 1990, and union formation and childbearing patterns of younger cohorts who enter young adulthood after 1990 may be substantially different.
} 
Table 2: Total first marriage rate $(T F M R)$, total divorce rate $(T D R)$, proportion of extramarital births and total fertility rate $(T F R)$ in the Czech Republic, Hungary, Italy, Spain, and The Netherlands in 1999

\begin{tabular}{|c|c|c|c|c|}
\hline & $T F M R$ & $T D R$ & $\begin{array}{c}\% \text { Extra- } \\
\text { marital } \\
\text { births }\end{array}$ & $T F R$ \\
\hline Bulgaria & 0.53 & 0.19 & 35.1 & 1.23 \\
\hline Czech Republic & 0.48 & 0.32 & 20.6 & 1.13 \\
\hline Hungary & 0.46 & 0.39 & 28.0 & 1.29 \\
\hline Italy & 0.62 & 0.08 & 9.2 & 1.23 \\
\hline Spain & 0.61 & 0.15 & 16.3 & 1.20 \\
\hline The Netherlands & 0.60 & 0.37 & 22.7 & 1.65 \\
\hline
\end{tabular}

TFMR of 0.6 that is comparable to Italy and Spain, despite the fact that this country has been a forerunner of the Second Demographic Transition (the Netherlands differs in this respect from some Nordic countries, such as Sweden, that have total first marriage rates of .46). A similar clustering of lowest-low fertility countries occurs also with respect to the total divorce rate $(T D R)$ in 1999. Italy has the lowest $T D R$ of 0.08 , followed by Spain with a level of 0.15. All Central and Eastern European countries in Table 2 have higher total divorce rates (Bulgaria 0.19, the Czech Republic 0.32, Hungary 0.39), which are comparable or even higher than that in the Netherlands (0.37). A similarly heterogeneous pattern characterizes also the prevalence of extra-marital births in the lowest-low fertility countries in Table 2. Italy has a particularly low share of extramarital births $(9.2 \%)$ and is followed by Spain (16.3\%), while Bulgaria (35.1\%), the Czech Republic (20.6\%) and Hungary $(28.0 \%)$ exhibit a proportion of extramarital births that is comparable or even higher an that in the Netherlands (22.7) (for comparison, the proportion of extra-marital births in Sweden is $55.3 \%$ in 1999).

In summary, the above analyses further strengthen our argument that the aggregate cross-country relationship between partnership formation/dissolution and levels of fertility has become quite indeterminate in the late 1990s, which is strikingly different from the strong relations between fertility and union formation and dissolution that prevailed 20 years earlier. In addition, our analyses reveal important differences in home-leaving, union formation and dissolution between lowest-low fertility countries. On the one hand, the Southern European pattern is characterized by late separation from the parental household, a low prevalence of cohabitation and extra-marital fertility, and a high centrality of marriage with long-term commitments and low rates of divorce. On the other hand, the Central and Eastern European pattern is more diverse and characterized earlier homeleaving, lower rates of marriage and higher rates of divorce and extra-marital fertility than the Southern European pattern. 


\section{Fertility-related Patterns of Female Labor Market Partic- ipation}

In addition to witnessing a changing relation between fertility and marriage or divorce, the 1990s have also challenged the conventional wisdom about the relation between aggregatelevel $T F R$ and female labor force participation rates $(F L F P R)$. In particular, conventional economic theory predicts that increases in the wage rate of women lead to increases of female labor market participation on the one, and decreases of fertility on the other side due to increased opportunity costs of children in combination with a low income elasticity of the number of children (Becker 1981; Cigno 1991; Willis 1973). At the macro level, this relation has been translated into the hypothesis that the total fertility rate and the female labor force participation rate should be inversely related in cross-country studies.

In this section we investigate the empirical evidence for this hypothesis as part of our overall attempt in this paper to portrait the socioeconomic context of lowest-low fertility trends. In particular, several recent studies have documented a changing cross-country relationship between fertility levels and rates of female labor force participation. For instance, Ahn and Mira (2002), Engelhardt et al. (2001) and Kögel (2001) have shown that the cross-country correlation between the total fertility rate and the FLFPR has changed its sign in OECD countries during the mid 1980s and early 1990s. This finding is also confirmed in regression-based analyses (Brewster and Rindfuss 2000; Esping-Andersen 1999), where female labor force participation rates are have a positive (and significant) influence on the TFR in cross-sectional analyses of OECD countries in the 1990s, while comparable analyses for the 1970s reveal a negative influence.

This reversal of the relation between is depicted in Figure 9 that plots the 1975 and 1996 TFR levels against the corresponding female labor force participation rates (we focus in Figure 9 on in Western Europe, where female labor force participation has traditionally been very different between countries; Central and Eastern European countries had a very high female labor force participation prior to 1990, while female labor force participation has been difficult to assess during the transition process due to a widespread shadow economy and incomplete employment registration). ${ }^{8} \quad$ In 1975 , countries with a high $F L F P R$, such as Sweden or Denmark, exhibited low fertility in a European comparison, while countries with low FLFPR, such as Italy or Spain, had relatively high fertility. In 1996, high FLFPR is associated with high fertility, such as in Denmark and Sweden, while lowest-low fertility countries such as Italy and Spain are characterized by only quite modest participation of females in the labor market. It is also important to note that changes fertility levels - rather than changes in female labor force participation rateshave been more prevalent in the countries in Figure 9, and the relative country-positions with respect to female labor force participation have been remarkably constant during the period 1975-96 (e.g., see the labeled points in the figure).

The above findings about the changing association between TFR levels and female labor force participation has spurred several additional analyses that investigate this issue further. Ahn and Mira (2002), for instance, emphasize the relevance of Mediterranean

\footnotetext{
${ }^{8}$ We are also grateful to Tomas Kögel who has provided us with the data for these analyses.
} 
Figure 9: Female labor force participation rate and TFR, 1975 and 1996

(a) TFR and female labor force participation: 1975

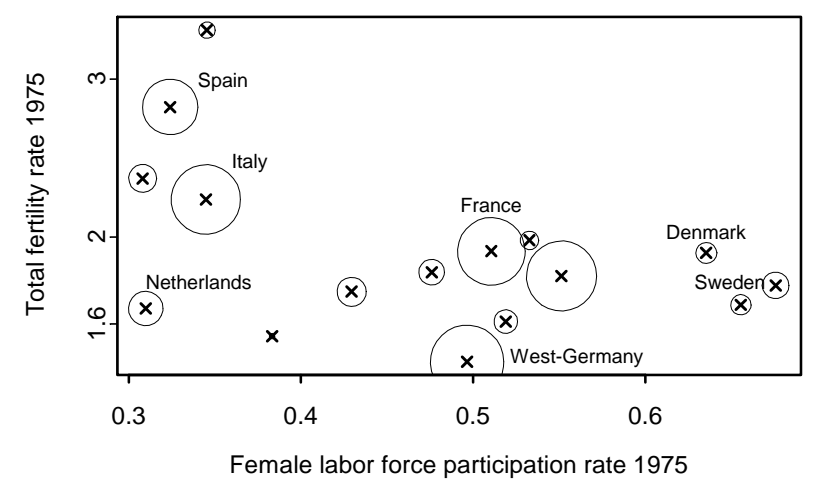

(b) TFR and female labor force participation: 1996

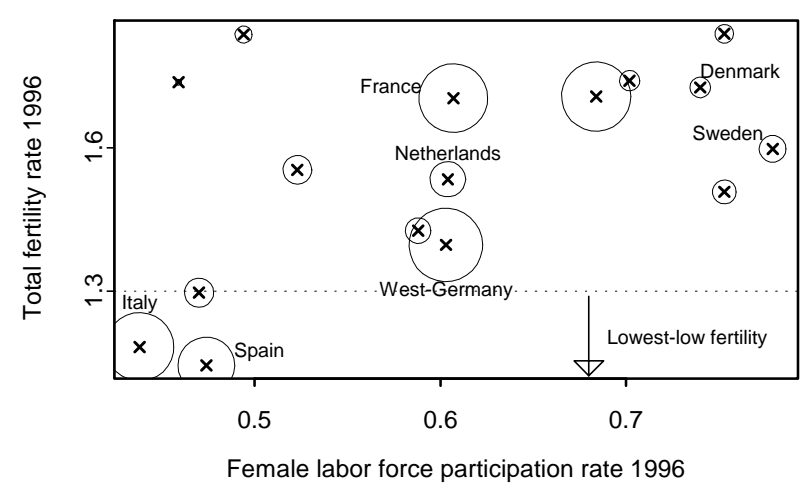

Note: TDR for Spain is for 1995. The ' $x$ ' mark gives the exact position of a country, while the area of circle is proportional to the country's population size in 1990. Source for data: Kögel (2001)

countries in the above pattern because the emergence of lowest-low fertility is an important factor contributing to the reversal of the correlation. Brewster and Rindfuss (2000) also emphasize the role of institutional arrangements, e.g., different family policies, child-care systems or welfare state typologies, and they stress the altered social norms regarding the combination between childrearing and labor market participation of women. Specifically, lowest-low fertility in Southern Europe has occurred in a context with very low compatibility of fertility and female labor market participation, which is due to the difficulties in entering and re-entering the labor market and the limited flexibility of working hours (Bettio and Villa 1998).

Obviously, the above studies cannot make inferences about causality due to their reliance on relatively simple aggregate data and analyses. One attempt to overcome this limitation is conducted by Engelhardt et al. (2001) who study macro-level time-series data for France, West Germany, Italy, Sweden, the United Kingdom, and the United States. The study shows that macro-level causality — or specifically, Granger causality (e.g., see Granger 1969; Hamilton 1994) — occurs in both directions, that is, from female labor force participation to fertility, and vice-versa. In addition, the study supports the above crosssectional evidence in Figure 9 and finds that the negative association between the TFR and the female labor force participation rate has become weaker over time for each indi- 
vidual country towards the end of the 1980s and beginning of the 1990s, and for selected countries it has even reversed. An exception is Italy, where the negative association over time between the TFR and FLFPR has not weakened at all. These conclusions, however, are partially challenged by Kögel (2001), who finds that there has not been a change in sign of the association between TFR and FLFPR over time if analyses account for country-specific fixed effects. Nevertheless, even after controlling for country-specific effects, Kögel's analyses conclude that the negative association between fertility and FLFPR has weakened over time, and the analyses also emphasize that the fertility decline in the Mediterranean countries has been an important factor contributing to the shifting relation in Figure 9.

\section{Concluding Discussion: Divergent Fertility Patterns in a Comparative Perspective}

In the previous sections we have argued that the emergence of lowest-low fertility marks a discontinuity with past trends that widens the heterogeneity among European countries with respect to fertility levels. In addition, we have demonstrated that several well-known cross-country relationships between fertility and marriage, divorce and female labor force participation need to be questioned and reconsidered in light of the most recent trends.

In this concluding discussion we utilize the above insights in order to evaluate whether developed countries, and in particular European countries, converge with respect to their fertility and fertility-related behavioral patterns, or alternatively, whether the countries will be characterized by persistent diversity. The relevance of convergence has recently been stressed in the context of the demographic transition from high to low fertility (Wilson 2001), and a similar reasoning suggests that it is of equal or even greater importance for understanding fertility trends and life-course patterns in contexts with below-replacement fertility. For instance, Mayer (2001) observes that long-standing differences in social and economic institutions between Western European countries play a decisive role in determining the impacts of economic globalization on life course patterns, and he suggests that at least four 'ideal types' of society can be identified within Western Europe and North America: the Scandinavian social democratic welfare states (e.g., Sweden); the continental conservative welfare states (e.g., Germany); the Southern European welfare states (e.g., Italy), and the liberal market states (e.g., UK, USA) (see also Esping-Andersen 1999). These different and often rigid institutional arrangements affect - as one would expect on the basis of conscious and rational life-course decision-making - the timing and sequence of key life-course events, such as marriage or births, and institutional differences thus partially explain the different life courses chosen by individuals in the various developed countries.

In addition to these institutional factors, Reher (1998) emphasizes enduring differences in family systems. In particular, he contrasts family patterns in Southern Europe, which are predominantly characterized by 'strong' ties (Granovetter 1973, 1985), with the family ties in North-Western Europe, where 'weak ties' have been typical of family relations for several centuries. Reher stresses in this context that these different types of family 
ties exert a significant impact on current life-course patterns in early adulthood, and he concludes that the "divergent practices [of contemporary life-course transitions] appear to have deep historical roots" (p. 205). The arguments of Mayer (2001) and Reher (1998) can thus be seen as identifying two separate forces. Mayer's line of argument emphasizes the path-dependence of institutions, while Reher's work stresses the initial conditions of family organization that underly the evolution family and marriage patterns in modern European societies.

In contrast to the above studies focusing on the determinants of persistent differences in fertility and fertility-related behaviors between countries, other scholars have emphasized long-term convergence. Watkins (1990), for instance, studies the fertility transition in Western Europe during the period 1870-1960 and argues that regional diversity within countries diminish, which is in part due to an increasing influences of national instead of local channels of social interactions (e.g., through national media). A further argument suggesting convergence between countries is often derived from the Second Demographic Transition theory (Lesthaeghe and van de Kaa 1986; van de Kaa 1987), which argues that demographic behavior in developed countries becomes increasingly less constrained by societal norms and is instead more strongly based on individual considerations of the costs and benefits of alternative types of family life. The theory also proposes that demographic change is closely linked to ideational sifts towards more postmodern, individualistic and post-materialistic value orientations, and as a consequence, family forms and fertility behavior are becoming increasingly diverse within cohorts.

Although the notion of convergence is not explicitly expressed in the initial formulations of the Second Demographic Transition theory, the Netherlands and Nordic countries were often portrayed as forerunners of demographic changes gradually leading to more diverse life-courses in all contemporary European countries. In particular, the theory envisions that over time all European countries become characterized by low fertility and a high prevalence of new behavioral patterns such as delayed union formation after leaving the parental home, cohabitation, out-of-wedlock childbearing, and divorce.

In order to investigate the above notion of convergence, Billari and Wilson (2001) have conducted an analysis of early life-course transition, such as leaving home, first union, first marriage and first birth, in nine Western European countries. The analyses are based on the Fertility and Family Surveys that have been conducted in many European countries during the 1990s (e.g., see Klijzing and Corijn 2002), and they compare the experience of five-year birth cohorts born from 1946-50 to 1961-65. An important result of these analyses is that there is no strong indication for convergence with respect to many fertility and fertility-related behaviors; quite on the contrary, there has been remarkably little convergence with respect to important life-course patterns such as the sequencing of first birth and first marriage or the prevalence of cohabitation in early adulthood. Figure 10(a), for instance, depicts the share of women starting the first union before marriage. Not surprisingly, Sweden is at the forefront of the diffusion of non-marital first unions: cohabitation prior to marriage was already widespread for the cohort 1946-50 and the share of women having a non-marital first union prior to marrying reaches almost $100 \%$ in the most recent cohort (1961-65). At the other extreme of the diffusion of non-marital 
Figure 10: $(a)$ Share of women starting a consensual union before first marriage in selected Western European countries; $(b)$ share of women having a birth before first marriage in selected Western European countries

(a) First union before marriage

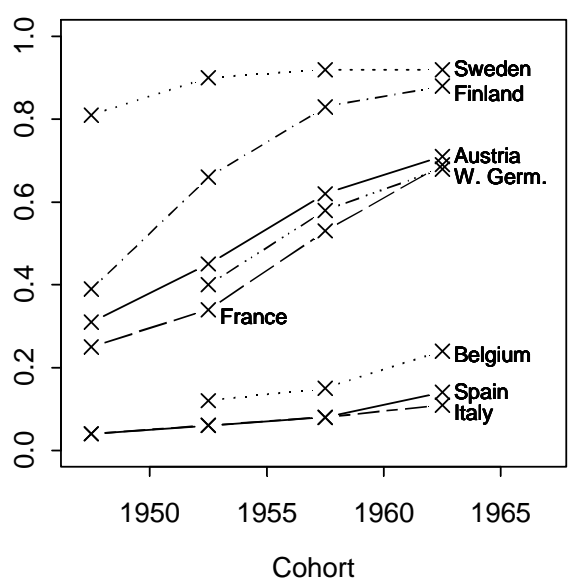

(b) First birth before marriage

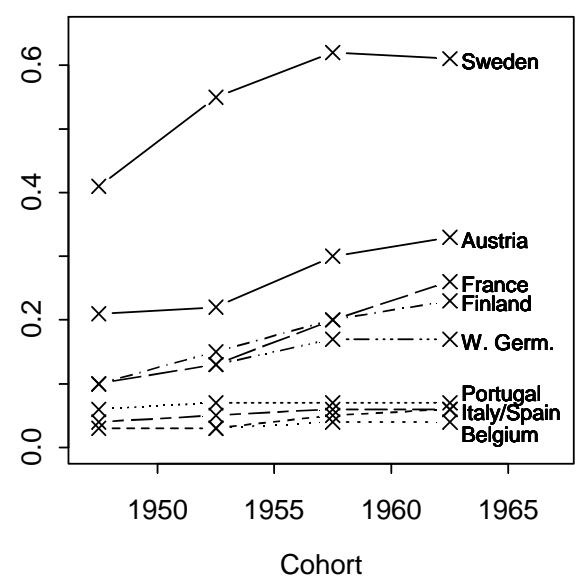

Note: The data for Belgium pertain only to the Flemish part of Belgium. Source: Billari and Wilson (2001)

first unions are two Southern European countries with lowest-low fertility, Italy and Spain. Albeit the share of women starting to cohabit in their first union in these countries is rising as well, the levels are still very low (11\% in Italy and 14\% in Spain for the 1961-65 cohort). Between the extreme cases marked by Sweden on the one and Italy/Spain on the other side, Figure 10(a) includes several other European countries with fertility levels above the lowest-low threshold of a TFR of 1.3.

Figure 10(b) presents a further example for a differential sequencing across European countries of important life-course events in young adulthood across, which supports the above argument about limited convergence in life-course patterns. In particular, Figure 10(b) presents the share of women who give birth to a child before getting married and it reveals that Sweden is again at the forefront of the diffusion of extra-marital fertility. The cohort born 1946-50 in Sweden had already the highest share of women who give birth prior to the first marriage among all countries in Figure 10(b), and this level already exceeds the level attained by all other countries for last cohort born 1961-65. This share has further increased in Sweden over time, and it attains a level of $61 \%$ in the most recent cohort. The other extreme of the pattern is represented by the lowest-low fertility counties Italy and Spain, along with Portugal and Belgium, that all exhibit proportions of first births prior to first marriage below $8 \%$. In addition, the country ranking is relatively stable across cohorts, and there have been no movements between the three clusters with low, moderate and high levels of first births before marriage.

In summary, the patterns of lowest-low fertility portrayed in this paper allow us to draw first conclusions about the determinants and macro-level covariates of low and lowest-low fertility in contemporary Europe. First, our portrait of contemporary European fertility patterns identifies a systematic pattern of lowest-low fertility that is characterized by a rapid delay of childbearing, a low progression probability after the first child (but not 
particularly low levels of first-birth childbearing), a "falling behind" in cohort fertility at relatively late ages (in Southern Europe) and a reversal in the relative ranking of lowest-low fertility countries in a European comparison of TFR levels. At the end of the 1990s, therefore, there emerges a clear clustering of European nations separating them into countries with moderately high fertility levels and countries with lowest-low fertility, and this clustering is mirrored in many fertility-related behaviors such as female labor force participation, the diffusion of cohabitation or out-of-wedlock childbearing and other dimensions.

Second, lowest-low fertility countries are themselves heterogeneous and cluster into two distinct patterns. On the one hand, Southern European lowest-low fertility countries, including foremost Italy and Spain, exhibit also latest-late home-leaving behavior, a limited spread of non-marital cohabitation, a low share of extramarital births, a limited diffusion of divorce, and a relatively low share of women participating in the labor force. They also exhibit a more marked postponement of first births and a lower recuperation of fertility at higher ages. On the other hand, Central and Eastern European countries, represented in our analyses by Bulgaria, Czech Republic and Hungary, exhibit relatively earlier household independence, union formation. They also they have higher non-marital fertility and divorce rates, and first births take place earlier than in Southern European lowest-low fertility countries.

Third, many behavioral patterns characteristic for lowest-low fertility countries have been subject to remarkably little convergence, and our analyses suggest that many of the above characteristics of lowest-low fertility countries, and their differences with other European or developed countries, are subject to path-dependent evolution and are thus likely to persist in the near- and medium-term future.

Fourth, the emergence of lowest-low fertility during the 1990s has been accompanied by a disruption or even a reversal of many well-known patterns that have been used to explain cross-country differences in fertility patterns. For instance, the cross-sectional correlations European countries between the total fertility level on the one side, and the total first marriage rate, the proportion of extramarital births and the female labor force participation rate on the other side have reversed during the period from 1975 to 1999. At the end of the 1990s there is also no longer evidence that divorce levels are negatively associated with fertility levels. Hence, there are crucial changes in the relationship between traditional determinants of fertility - such as marriage, divorce, home-leaving and female labor force participation - and fertility before and after the emergence of lowest-low fertility, and perhaps most importantly, there is a clear indication that a high prevalence of marriage and institutionalized long-term partnership commitments are no longer associated with higher fertility in cross-sectional comparisons. While the detailed analysis of the determinants of this reversal is beyond the scope of the present paper, one fundamental cause can probably not be disputed: The reversal in cross-sectional associations between fertility and related behaviors is in part due to the different demographic factors driving fertility change. Initially, the decline towards low fertility has been importantly related to stopping behavior, that is, a reduction of higher parity births. More recently, the postponement of fertility - particularly for first births - has emerged as a crucial determinant 
of differences in fertility levels among developed countries.

Concluding this paper, we also emphasize an important caveat of our descriptive analyses that do not necessarily identify causal relations; causal patterns are almost impossible to disentangle with the aggregate-level data used in these introductory investigations. The patterns we have described may either be part of a complex web of causation where fertility and fertility-related factors influence each other, or they may just be the indication that other general factors are simultaneously driving changes in fertility and fertility-related behaviors.

\section{References}

Ahn, N. and P. Mira (2002). A note on the changing relationship between fertility and female employment rates in developed countries. Journal of Population Economics, forthcoming.

Becker, G. S. (1981). A Treatise on the Family. Cambridge, MA: Harvard University Press.

Bettio, F. and P. Villa (1998). A Mediterranean perspective on the breakdown of the relationship between participation and fertility. Cambridge Journal of Economics 22(2), $137-171$.

Billari, F. C., P. Manfredi, and A. Valentini (2000). Macro-demographic effects on the transition to adulthood: Multistate stable population theory and and application to italy. Mathematical Population Studies 9(1), 33-63.

Billari, F. C., D. Philipov, and P. Baizán (2001). Leaving home in Europe: The experience of cohorts born around 1960. International Journal of Population Geography 7(5), 339356.

Billari, F. C. and C. Wilson (2001). Convergence towards diversity? Cohort dynamics in the transition to adulthood in contemporary western europe. Max Planck Institute for Demographic Research, Rostock, Germany, Working Paper \#2001-039 (available at http://www.demogr.mpg.de).

Bongaarts, J. (1978). A framework for analyzing the proximate determinants of fertility. Population and Development Review 4 (1), 105-132.

Bongaarts, J. and R. A. Bulatao (Eds.) (2000). Beyond Six Billion: Forecasting the World's Population, Washington, DC. National Academy Press.

Brewster, K. L. and R. R. Rindfuss (2000). Fertility and women's employment in industrialized nations. Annual Review of Sociology 26, 271-296.

Cigno, A. (1991). Economics of the Family. Oxford: Clarendon Press.

Coleman, D. (Ed.) (1996). Europe's Population in the 1990s, Oxford. Oxford University Press. 
Corijn, M. (1999). Transitions to adulthood in europe for the 1950s and 1950s cohorts. Brussels: CBGS-Werkdocument \#4.

Cornia, G. A. and R. Paniccià (2000). The Mortality Crisis in Transitional Economies. Oxford: Oxford University Press.

Council of Europe (2001). Recent Demographic Developments in Europe. Strasbourg: Council of Europe Publishing.

Engelhardt, H., T. Kögel, and A. Prskawetz (2001). Fertility and female employment reconsidered: A macro-level time series analysis. Max Planck Institute for Demographic Research, Rostock, Germany, Working Paper \#2001-021 (available at http:// www.demogr.mpg.de).

Esping-Andersen, G. (1999). Social Foundations of Postindustrial Economies. Oxford: Oxford University Press.

Fernández Cordón, J. A. (1997). Youth residential independence and autonomy: a comparative study. Journal of Family Issues 16(6), 567-607.

Frejka, T. (1980). Fertility trends and policies: Czechoslovakia in the 1970s. Population and Development Review 6(1), 65-93.

Frejka, T. and G. Calot (2001a). Cohort reproductive patterns in low-fertility countries. Population and Development Review 27(1), 103-132.

Frejka, T. and G. Calot (2001b). Cohort reproductive patterns in the Nordic Countries. Demographic Research [online available at http://www.demographic-research.org] 5(5), $125-186$.

Frejka, T. and G. Calot (2001c). L'évolution du calendrier des naissances par génération dans les pays à basse fécondité à la fin du XXe siècle. Population 56 (3), 397-420.

Granger, C. W. J. (1969). Investigating causal relations by economic models and crossspectral methods. Econometrica 37(3), 424-438.

Granovetter, M. S. (1973). The strength of weak ties. American Journal of Sociology 78(6), $1360-1380$.

Granovetter, M. S. (1985). Economic action and the social structure: The problem of embeddedness. American Journal of Sociology 91(3), 481-510.

Hajnal, J. (1965). European marriage pattern in perspective. In G. D. V. and D. E. Eversley (Eds.), Population in History: Essays in Historical Demography, pp. 101-143. Chicago, Illinois: Aldine Publishing Company.

Hamilton, J. D. (1994). Time Series Analysis. Princeton: Princeton University Press.

Henry, L. (1976). Population: Analysis and Models. London: Edward Arnold. 
Inaba, H. (1996). Human population reproduction via first marriage. Mathematical Population Studies 5(2), 123-144.

Kiernan, K. (1986). Leaving homei Living arrangements of young people in six WestEuropean Countries. European Journal of Population 1(2), 177-184.

Kiernan, K. (1999). Childbearing outside marriage in Western Europe. Population Trends 98, 11-20.

Klijzing, E. and M. Corijn (Eds.) (2002). Fertility and Partnership in Europe: Findings and Lessons from Comparative Research, Volume 1-2, Geneva / New York. United Nations.

Kögel, T. (2001). Did the association between fertility and female employment in oecd countries really change its sign? No. Max Planck Institute for Demographic Research, Rostock, Germany, Working Paper \#2001-034 (available at http://www.demogr.mpg.de).

Kohler, H.-P. (2001). Fertility and Social Interactions: An Economic Perspective. Oxford: Oxford University Press.

Kohler, H.-P., J. R. Behrman, and S. C. Watkins (2001). The density of social networks and fertility decisions: Evidence from South Nyanza District, Kenya. Demography 38(1), $43-58$.

Kohler, H.-P., F. C. Billari, and J. A. Ortega (2002). Towards a theory of lowest-low fertility. Population and Development Review, forthcoming. (earlier version available as MPIDR Working Paper \#2001-032 at http://www.demogr.mpg.de).

Kohler, H.-P. and I. Kohler (2002). Fertility decline in Russia: Social versus economic factors. European Journal of Population 18(3), forthcoming.

Kohlmann, A. and S. Zuev (2001). Patterns of childbearing in Russia 1994-1998. Max Planck Institute for Demographic Research, Rostock, Germany, Working Paper \#2001018 (available at http://www.demogr.mpg.de).

Kreyenfeld, M. (2002). Employment and fertility: East Germany in the 1990s. Doctoral Dissertation, University of Rostock and Max Planck Institute for Demographic Research, Rostock, Germany.

Kučera, T., Kučerová, O. B. Opara, and E. Schaich (Eds.) (2000). New Demographic Faces of Europe: The Changing Population Dynamics in Countries of Central and Eastern Europe, Berlin. Springer Verlag.

Lesthaeghe, R. (2001). Postponement and recuperation: Recent fertility trends and forecasts in six Western European Countries. Interface Demography, Vrje Universiteit, Brussels, Belgium. IPD Working paper 2001-01 (Available at http:// www.vub.ac.be/soco/index.htm). 
Lesthaeghe, R. and D. van de Kaa (1986). Twee demografische transities? In R. Lesthaeghe and D. van de Kaa (Eds.), Bevolking: Groei en Krimp, pp. 9-24. Deventer: Van Loghum Slaterus.

Lutz, W., W. Sanderson, and S. Scherbov (2001). The end of world population growth. Nature 412, 543-545.

Mayer, K. U. (2001). The paradox of global social change and national path dependencies: Life course patterns in advanced societies. In A. E. Woodward and M. Kohli (Eds.), Inclusions and Exclusions in European Societies, pp. 89-110. London: Routledge.

Modell, J., F. F. Furstenberg, and T. Hershberg (1976). Social change and transitions to adulthood in historical perspective. Journal of Family History 1(1), 7-32.

Monnier, A. and J. Rychtarikova (1992). The division of Europe into East and West. Population: An English Selection 4, 129-159.

Montgomery, M. R. and J. B. Casterline (1996). Social learning, social influence, and new models of fertility. Population and Development Review 22(Suppl.), 151-175.

Philipov, D. (2001). Low fertility in Central and Eastern Europe: Culture or economy? Paper presented at the IUSSP Seminar on International Perspectives on Low Fertility: Trends, Theories and Policies. Tokyo, Japan, March 21-23.

Reher, D. S. (1998). Family ties in Western Europe: Persistent contrasts. Population and Development Review 24(2), 203-234.

van de Kaa, D. J. (1987). Europe's second demographic transition. Population Bulletin 42(1), 1-59.

van Imhoff, E. (2001). On the impossibility of inferring cohort fertility measures from period fertility measures. Demographic Research [online available at http:// www.demographic-research.org] 5(2), 23-64.

Watkins, S. C. (1990). From local to national communities: The transformation of demographic regimes in Western Europe, 1870-1960. Population and Development Review 16(2), 241-272.

Willis, R. J. (1973). A new approach to the economic theory of fertility behaviour. Journal of Political Economy 81(2, pt. 2), 14-64.

Wilson, C. (2001). On the scale of global demographic convergence 1950-2000. Population and Development Review 27(1), 155-172. 


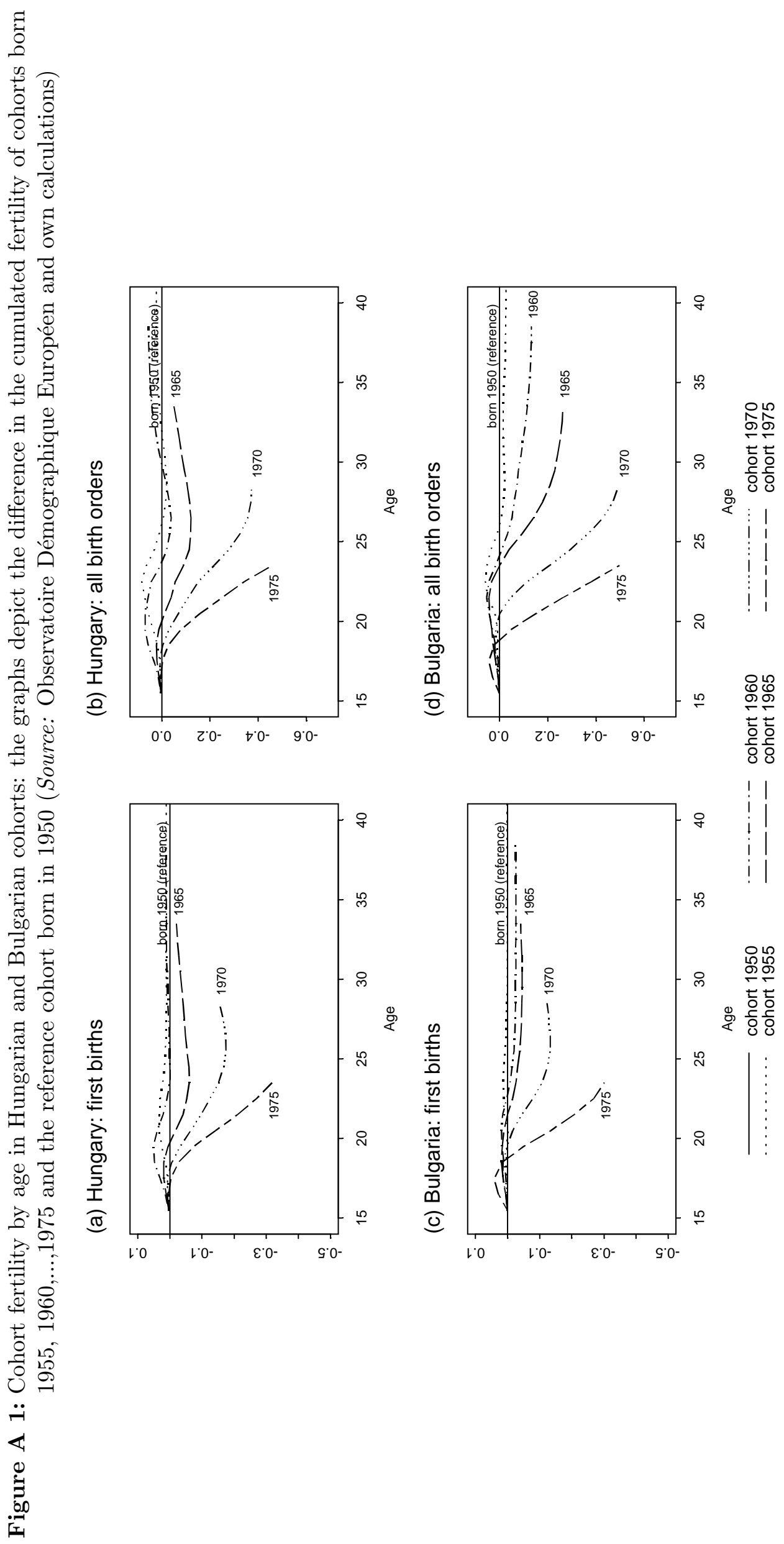




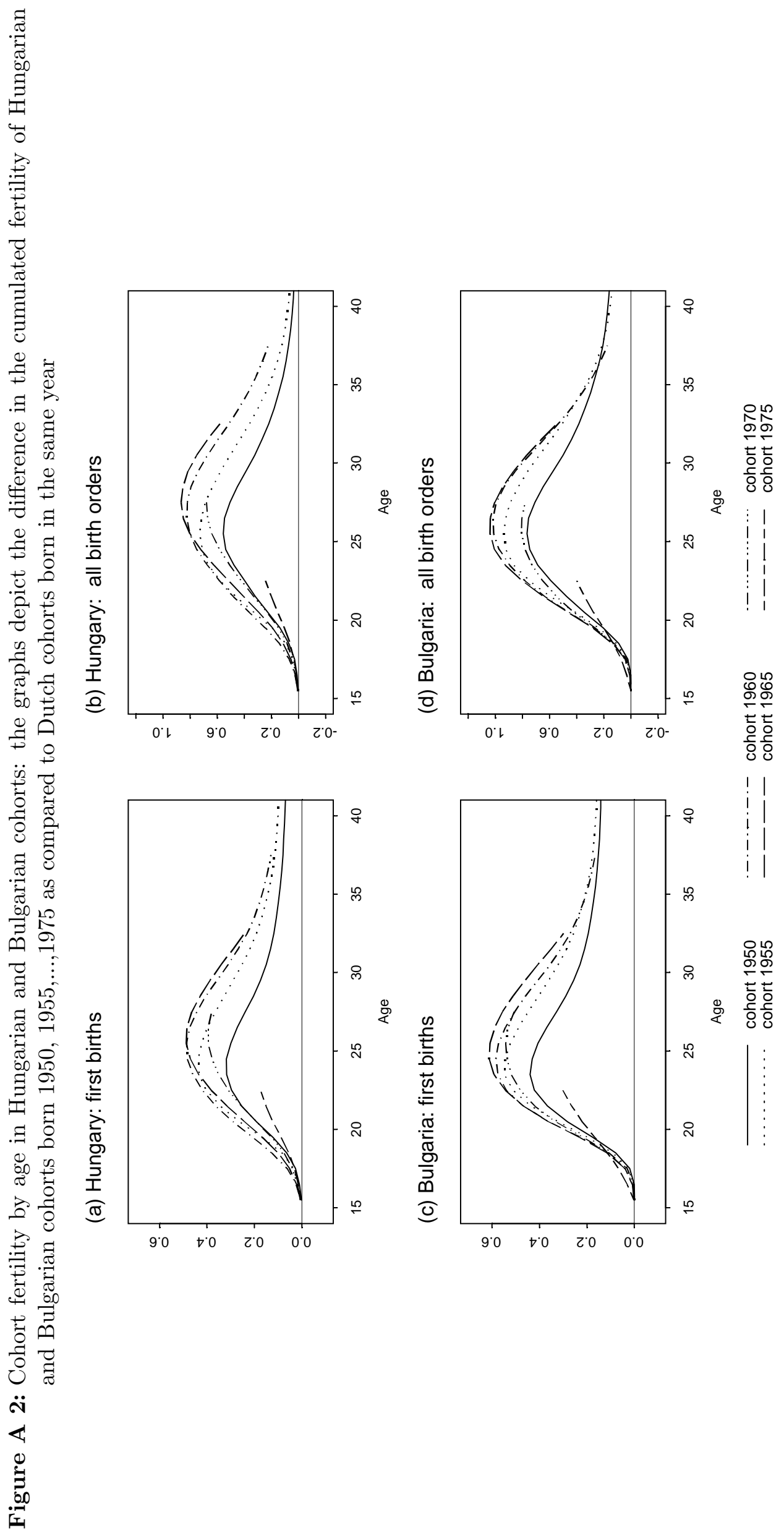

